\title{
Substance use, risky sexual behaviors, and their associations in a Chinese sample of senior high school students
}

Shenghui Li $i^{1,2^{*}}$, Hong Huang ${ }^{2,3^{*}}$, Gang $X u^{1}$, Yong Cai ${ }^{1}$, Fengrong Huang ${ }^{2}$ and Xiuxia Ye ${ }^{2}$

\begin{abstract}
Background: Given the higher prevalence of risky sexual behaviors and substance use, adolescents and youths are at risk for HIV. Despite its importance, however, to the best of our knowledge, there are only a few researches on risky behaviors in Chinese adolescents/youths. The present study aimed to describe the prevalence of sexual and substance use behaviors among a Chinese sample of senior high school students. And more specifically, the associations of socio-demographic factors and substance use with risky sexual behaviors were examined in the sample.
\end{abstract}

Methods: A cross-sectional study was conducted in 10 senior high schools. A total of 2668 senior high school students aged 15.17 to 23.42 years participated in the survey. A self-administrated questionnaire was used to collect information on sexual and substance use behaviors.

Results: The percentages of students who ever had sexual intercourse in lifetime or during last three months were $7.0 \%$ and $5.1 \%$, respectively. Among the participants with sexual intercourse during last three months, $42.1 \%$ ever had unprotected sexual intercourse and $49.4 \%$ had intercourse with two or more partners. Multivariate logistic regression analyses showed that cigarette smoke and illicit drug use were related to unprotected sexual intercourse (defined as "sexual intercourse without condom use") and younger age of first sexual intercourse was related to multiple-partner sexual intercourse.

Conclusions: HIV/sexual transmitted infection (STI) health education and prevention are necessary among the Chinese adolescents, particularly among those adolescents with experience of sexual intercourse and/or substance use, which has a long-term beneficial to the control of HIV/STI in China.

Keywords: HIV/STI, Sexual behavior, Substance use, Adolescent, China

\section{Background}

Adolescence/youth is often characterized as a stage of increased imitation and exploration with a range of risky behaviors, including risky sexual behaviors and substance use [1-5]. Previous studies revealed that risky behaviors had the characteristic of clustering in one person [1-3,5,6]. For example, risky sexual behaviors (such as multiple sexual partners and unprotect sexual intercourse) among

\footnotetext{
* Correspondence: Lsh9907@163.com; HuangHong096@hotmail.com ${ }^{1}$ School of Public Health affiliated with Shangai Jiaotong University School of Medicine, 227 South Chongqing Road, Shangai, People's Republic of China ${ }^{2} \mathrm{MOE}$ - Shangai Key Laboratory of Children's Environmental Health, Xinhua Hospital, Shangai Jiao Tong University School of Medicine, Shangai, People's Republic of China

Full list of author information is available at the end of the article
}

adolescents and youths have been shown to be easy to cooccur with a range of other risky behaviors including alcohol drinking, cigarette smoking, drug use, and violence [1,2,6-8]. In turn, substance use and violence have been implicated in increasing the likelihood for participation in risky sexual behaviors [1,5-7].

A recent report on risky behaviors among American adolescents and youths aged 10-24 years indicated that 4.4\% ever had used illicit drugs, $75.0 \%$ ever had drunk alcohol, $47.8 \%$ ever had sexual intercourse, and $38.5 \%$ of currently sexually active adolescents/youths had not used a condom [4]. Researches in other countries similarly found a higher prevalence of risky sexual behaviors and substance use in adolescents and youths [5,7-9].

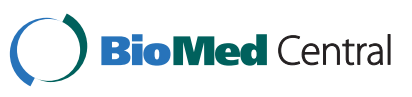


Given the higher prevalence of risky sexual behaviors and substance use, adolescents and youths aged 15 to 24 years represent approximately $25 \%$ of sexually active persons and account for nearly half of new HIV infection each year in the USA [10]. Therefore, adolescents and youths are important subpopulation for sexualrelated prevention and intervention efforts.

China is a developing country with a total population of approximately 1.3 billion. Of this 1.3 billion, $24.25 \%$ were adolescents and youths aged between 14 and 29 years in 2009 (State statistical bureau of the People's Republic of China, 2009). With the rapid economic development, sociocultural changes, and globalization, Chinese adolescents and youths are becoming more and more sexually active and easily access to substance use [11-14]. Shangai, the biggest city and metropolises in China, attracts many people of other districts and even other countries to settle and is labeled as a migration city. The ongoing social, cultural, value, and belief mixing may promote the upward trend of exposure to risk behaviors and substance use in adolescents and youths.

Despite its importance, however, to the best of our knowledge, there are only a few researches on risky behaviors in Chinese adolescents/youths. For example, several reports demonstrated that the prevalence of lifetime sexual intercourse was ranged from $1.3 \%$ to $4.8 \%$ in Chinese senior high school students [11-14]. An earlier survey on drug/psychoactive substance use among adolescents/youths in a south-west province showed the prevalence of substance use were, in rank order, tobacco $4.2 \%$, alcohol $1.6 \%$, NSAID $0.8 \%$, sedative/hypnotic $0.1 \%$, solvents $0.1 \%$, and cannabis $0.1 \%$ [15]. A more recent study in Yunnan province found that, among illicit drug user, $64.96 \%$ was adolescents and youth $(\leq 18$ years, $4.54 \%, 18-25$ years, $60.4 \%$ ) and $80 \%$ of drug users have sexual intercourse experience [16].

During recent years, the growth of the HIV/AIDS epidemic in China is slowing down [17-19]. However, the challenges for HIV/AIDS control are ever bigger than before due to the major shifts in the route of HIV transmission in China: from parenteral to sexual, from high-risk groups to the general population [17-19]. Sexual contact continues to be the major and increasing route of HIV transmission [17-19]. In the context of the efforts to control the transmission of HIV, a full understanding of risky sexual behaviors among general adolescents and youth are of particularly necessary. This necessity is further underscored by the fact that most published studies on risky sexual behaviors mainly focus on high-risk groups. This study filled this knowledge gap by describing the prevalence of sexual risk behavior and substance use engagement by socio-demographic factors among a sample of Chinese high school students. In addition, given unprotected and multiple- partner sexual contact being the most common mode of sexual transmission of HIV infection among adolescents and youth [17-20], we particularly explored the risk factors of ongoing unprotected sexual intercourse and multiple-partner sexual intercourse in the sample.

\section{Methods \\ Sample and procedure}

A cross-sectional survey, adopting a two-stage random cluster-sampling design, was conducted in Shangai, the biggest city in China, which is located in eastern coastal area with a total population of approximately 20.8 million in 2008 (State statistical bureau of the People's Republic of China, 2008) and the highest level of economic development in China. There are twenty districts in Shanghai, 11 being located in urban area, 9 in suburban, and 1 in rural area. From 11 urban districts, two were randomly selected and for every district, 5 senior high schools were randomly selected. All the students in selected schools yielded the sampling frame. Only those students who and their parent(s) both agreed and consented to participate in the study were recruited as eligible sample. Of 2995 students eligible for the study, 2688 (89.1\%) returned completed questionnaires. The mean age of the final sample was 17.17 years $(\mathrm{SD}=0.72$; range, $15.17-23.42$ years), $49.9 \%$ were males and $50.1 \%$ were females.

This study was conducted from April to June of 2008. The research aims were explained to school principals and teachers of the target schools. Permission was obtained from school board to carry out the study, which is the usual practice in China. Informed consent was distributed to all students at the schools, together with written information on the study and another copy of informed consent to be taken home by the children for their parents. After all informed consents had been returned, the survey was implemented during a regular health education class. In the class, an anonymous questionnaire was distributed to all the eligible students. Researchers explained the study purpose to the students and emphasized that participation was voluntary. Every student completed the questionnaire on his/her own desk and nobody else could see his/her responses. Those students who chose not to participate in the study were allowed to engage in other self-directed work, such as reading and writing. All students who did not attend the class were excluded from our survey.

The study protocol was approved by the Ethics Committee of Shanghai Jiaotong University School of Medicine.

\section{Measure}

\section{HIV/STI risk behaviors}

The Adolescents' HIV/STI Risk Behaviors Questionnaire (AHRBQ), a self-administrated questionnaire, was used to collect information on adolescents/youths' behaviors 
related to sex and substance use. The AHRBQ was derived from our previously established instrument “The Adolescents' Reproductive Health Questionnaire (ARBQ)". The ARBQ was used to collect information on adolescents' knowledge, attitude, and behaviors concerning HIV/STI, which has been described previously [21]. Based on the 10 items regarding HIV/STI related behaviors in ARBQ, the AHRBQ was developed by adding 9 items according to an updated literature review, qualitative interview in pilot study, and reliability assessment.

The final version of the AHRBQ included 19 items, in addition to demographic items, and the 19 items were conceptually grouped into 3 dimensions: - exposure to sexual behaviors in lifetime (6 items); exposure to sexual behaviors in last three months (9 items); exposure to drug-use behaviors in last three months (4 items) (see Additional file 1). Specific frame for each item of the subscale was noted in Table 1.

The internal consistency of the three dimensions of the AHRBQ was good (Cronbach's alpha coefficient was ranged from 0.71 to 0.77 ). The test-retest reliability was evaluated over two week period in a subgroup of our sampled students $(n=256)$ and found to be satisfactory (Intraclass correlation coefficients was 0.85 for the overall questionnaire and ranged from $0.69-0.75$ for the dimensions).

\section{Socio-economic and demographic characteristics}

This section consisted of participant's gender, age, grade, parents' education levels and occupation, household income [RMB(yuan)/person/month], parents' relationship, and family structure (i.e., single parent family, nuclear family, or extended family).

In our study, a family including children, parents, grandfather and/or grandmother, who live together, was defined as extended family; a family including children and parents was defined as nuclear family; and a family only including children and father or mother was defined as single-parent family.

In China, there are no established systems to assess the socioeconomic status (SES) of individual family.

Table 1 The response scales for sexual/drug-use behaviors in the AHRBQ

\begin{tabular}{|c|c|c|c|c|}
\hline & \multicolumn{4}{|c|}{ Response scale } \\
\hline & 1 & 2 & 3 & 4 \\
\hline \multicolumn{5}{|l|}{ Part one Sexual behaviors in lifetime; } \\
\hline 1. Sexual intercourse in lifetime & yes & no & & \\
\hline 2. Gender of the sexual partner lifetime & heterosexual & homosexual & both & \\
\hline 3. Sexual intercourse partners in lifetime & one & two & three & \\
\hline 4. Unprotected sexual intercourse & yes & no & & \\
\hline 5. Age of the first sexual intercourse & $\leq 14$ years & $15-17$ years & $\geq 18$ years & \\
\hline 6. Age of the first sexual partner & $\leq 14$ years & $15-17$ years & $\geq 18$ years & \\
\hline \multicolumn{5}{|l|}{ Part two Sexual behaviors in last three months; } \\
\hline 1. Antecedent sexual behaviors with heterosexual partner & no & occasional $(1<$ time/week $)$ & often (1-2 times/week) & usually ( $\geq$ times/week) \\
\hline 2. Antecedent sexual behaviors with homosexual partner & no & Occasional & often & usually \\
\hline 3. Sexual intercourse & no & Occasional & often & usually \\
\hline \multicolumn{5}{|l|}{ 4. Among these sexual intercourses } \\
\hline (1) Heterosexual intercourse & Ever had & Never had & & \\
\hline (2) Homosexual intercourse & Ever had & Never had & & \\
\hline (3) Sexual intercourse partners (\%) & Ever had & Never had & & \\
\hline (4) Unprotected sexual intercourse & Ever had & Never had & & \\
\hline (5). Sexual intercourse while drunk & Ever had & Never had & & \\
\hline (6) Sexual intercourse with high-risk partners & Ever had & Never had & & \\
\hline \multicolumn{5}{|l|}{ Part three Substance use behaviors in last three months; } \\
\hline 1. Injection drug use & yes & no & & \\
\hline 2. Oral/rhinal drug use & yes & no & & \\
\hline 3. Cigarette smoking & no & Occasional & often & usually \\
\hline 4. Alcohol drinking & no & Occasional & often & usually \\
\hline
\end{tabular}

Antecedent sexual behaviors refers to kiss and petting. Unprotected sexual intercourse refers to the sexual intercourse without condemn use. High-risk partners refer to people with HIV/AIDS/STI, people with drug use, and people with multiple sexual partners. 
Therefore, parental education levels and household income were used as indicators of the family SES.

\section{Statistical analysis}

Statistical descriptions were made by use of the mean, standard deviation and percentages. Demographic differences between males and females were analyzed by Independent-samples $t$ test and the Chi-square test. The Chi-square tests were also used to compare differences in prevalence of sexual/drug-use behaviors between males and females.

Multivariate logistic regression analyses were performed to examine the correlating factors of ongoing (defined as having the behavior within last three months) unprotected sexual intercourse (defined as "sexual intercourse without condom use") and multiple-partner sexual intercourse. All socio-economic and demographic characteristics variables, all substance use variables, and two variables related to sexual intercourse in lifetime (age of the first sexual intercourse and age of the first sexual partner) were entered into the models with the dependent variable designated as "1" if ever had unprotected sexual intercourse/multiplepartner sexual intercourse within last three months and " 0 " if there was no. Because of the extremely low prevalence of injection drug use and oral/rhinal drug use, a new variable of "Illict drug ues" was created when multivariate logistic regression analyses were performed. The responding scale of "Illict drug ues" is "ever had" if the response to injection drug use or/and oral/rhinal drug use was ever had, and "never had" if the response to injection drug use or/and oral/rhinal drug use were both never had.

The final multivariate models included variables retaining significance after a forward likelihood-ratio stepwise elimination procedure. Statistical tests of regression estimates or OR were based on Wald statistics.

All analyses were performed using the Statistical Program for Social Sciences (SPSS) for Windows, version 12.5. In the presentation of the results, the statistical significance was set at $\mathrm{p}<0.05$ (two tailed).

\section{Results}

Socio-economic and demographic characteristics of study sample by gender

Table 2 summarized the socio-economic and demographic outlines of the study sample by gender. 2688 senior high school students aged $17.17 \pm 0.72$ years participated the survey, $49.9 \%(\mathrm{n}=1324)$ were males and $50.1 \%(\mathrm{n}=1329)$ were females.

No significant differences were observed in age, family income, and family structure between the males and females. However, father's educational level and mother's educational level were statistically different between the two groups with the tendency of lower father's educational

Table 2 Socio-economic and demographic characteristics of study participants

\begin{tabular}{|c|c|c|c|c|}
\hline & Total $(\mathrm{N}=2688)$ & Males $(\mathrm{N}=1324)$ & Females $(\mathrm{N}=1329)$ & $t / x^{2}$ \\
\hline Age (years, mean $\pm S D$ ) & $17.17 \pm 0.72$ & $17.20 \pm 0.74$ & $17.14 \pm 0.70$ & $1.81^{\mathrm{a}}$ \\
\hline Family income (\%) & & & & $0.94^{\mathrm{b}}$ \\
\hline Low $(<1500)$ & 15.9 & 15.2 & 16.4 & \\
\hline Medium (1500-2499) & 33.3 & 33.2 & 33.6 & \\
\hline $\operatorname{High}(\geq 2500)$ & 50.8 & 51.6 & 50.0 & \\
\hline Family structure & & & & $7.73^{\mathrm{b}}$ \\
\hline Single parent family & 7.8 & 8.1 & 7.2 & \\
\hline Nuclear family & 66.0 & 63.7 & 68.5 & \\
\hline Large family & 26.2 & 28.1 & 24.2 & \\
\hline Father's education level (\%) & & & & $10.83^{* *}$ \\
\hline Middle school and below & 7.6 & 8.5 & 6.9 & \\
\hline High school & 45.6 & 42.4 & 48.7 & \\
\hline College and above & 46.8 & 49.2 & 44.5 & \\
\hline Mother's education level (\%) & & & & $7.08^{* b}$ \\
\hline Middle school and below & 9.4 & 9.3 & 9.6 & \\
\hline High school & 50.8 & 48.4 & 53.1 & \\
\hline College and above & 39.9 & 42.3 & 37.3 & \\
\hline
\end{tabular}

Family income was expressed in RMB(yuan)/person/month.

a Independent-samples t test.

${ }^{b} \mathrm{~K}^{*} 2$ Chi-square Test.

* $P<0.05$.

** $P<0.01$. 
levels $(\chi 2=10.83, \mathrm{p}<0.01)$, and lower mother's educational levels $(\chi 2=7.08, \mathrm{p}<0.05)$ in females.

\section{Sexual behaviors in lifetime}

Overall, the percentage of senior high school students who ever had sexual intercourse was 7.0\% $(\mathrm{n}=188)$. Compared with females, males had higher prevalence of sexual intercourse (male: $11.0 \%$ vs. female: $2.5 \%$, $\mathrm{p}<0.01)$. Among the sexually experienced adolescents, $80.5 \%, 6.0 \%$, and $13.5 \%$ reported heterosexual intercourse, homosexual intercourse, and bisexual intercourse, respectively; $39.6 \%$ reported two or more sexual partners; $42.4 \%$ reported ever had unprotected sexual intercourse; $65.6 \%$ reported had the first sexual intercourse under 18 years ( $\leq 14$ years:16.4\%; $15-17$ years: $49.2 \%$ ) (Table 3 , part one).

\section{Sexual behaviors in last three months}

During the three months before the survey, 5.1\% (male: $7.7 \%$ vs. female: $1.9 \%, \mathrm{p}<0.01$ ) of senior high school students ever had sexual intercourse. Among these sexually experienced participants, $88.1 \%$ reported ever had heterosexual intercourse, $42.9 \%$ reported ever had homosexual intercourse, $49.4 \%$ reported two or more sexual partners, $42.1 \%$ reported ever had unprotected sexual intercourse, 39.6\% reported ever had sexual 126 intercourse after drunk, and $25.9 \%$ reported ever had sexual intercourse with high-risk partners. Among these ongoing sexual behaviors, compared with females, males had higher prevalence of sexual intercourse after drunk (male: $43.9 \%$ vs. female: $20.0 \%, \mathrm{p}<0.05$ ). In addition, males had higher frequency of heterosexual antecedent behaviors (male: $7.5 \%$ vs. female: $2.6 \%, \mathrm{p}<0.01$ ) (Table 3 , part two).

\section{Substance use behaviors in last three months}

During the three months before the survey, $1.4 \%$ of sampled senior high school students reported ever had injection illicit drug use, $1.2 \%$ reported ever had oral/rhinal illicit drug use, $2.0 \%$ often/usually smoked cigarette, and $4.0 \%$ often/usually drunk alcohol. Compared with females, males had higher prevalence of all above substance use (Table 3, part three).

\section{Risk factors of unprotected sexual intercourse/multiple- partner sexual intercourse of last three months in study sample}

Multivariate logistic regression analyses were performed to examine the correlating factors of ongoing unprotected sexual intercourse/multiple-partner sexual intercourse in our study participants.

As indicated in Table 4, after controlling for sociodemographic factors, other substance use behaviors, and two variables related to sexual behaviors in lifetime, two factors in the final model were significantly associated with an increased likelihood of ongoing unprotected sexual intercourse: often/usually cigarette smoke $(\mathrm{OR}=2.04$, $\mathrm{p}<0.05)$ and ever had illicit drug use $(\mathrm{OR}=2.44$, $\mathrm{p}<0.05)$. For ongoing multiple-partner sexual intercourse, younger age of first sexual intercourse $(\mathrm{OR}=2.45, \mathrm{p}<0.05$ for age $\leq 14$ years, $\mathrm{OR}=1.94, \mathrm{p}<0.05$ for age between 15 to 17 years) was the significant risk factor.

\section{Discussion}

To the best of our knowledge, this study was the first to examine HIV/STI risk behaviors according to three dimensions- sexual behaviors in lifetime, sexual behaviors in last three months, and substance use behaviors in the last three months- in a large sample of urban Chinese high school students. Moreover, we particularly explored the association of substance use and socio-demographic factors with ongoing unprotect sexual intercourse and multiple-partner sexual intercourse.

Overall, our study demonstrated that the proportions of senior high school students who ever had sexual intercourse in lifetime or during last three months were $7.0 \%$ and $5.1 \%$, respectively. A number of previous studies revealed that the prevalence of lifetime sexual intercourse was ranged from $1.3 \%$ to $4.8 \%$ in Chinese senior high school students [11-14,22,23]. In studies of other countries, adolescents who ever had sexual intercourse was $48.7 \%$ in the United Sates (aged 10-24 years) [4], 38\% in Italy (aged 14-19 years) [24], 17-46\% in South African (aged 13-17 years) [25], 11\% in Burkina Faso (aged 12-19 years) [26], 18-22\% in Nigerian (aged $15-19$ years) [27], and 5.1-56.6\% in Turkey (aged 16-20 years) $[28,29]$. The disparity in the prevalence of sexual intercourse among adolescents of different countries may be due to different sample characteristics, different traditional cultural background, and different socioeconomic environment.

Among sexually experienced adolescents, a higher prevalence of unprotected sexual intercourse (42.4\% in lifetime and $42.1 \%$ in last three months) was found in this sample of urban Chinese students compared their peers of developed countries [4,30,31]. Studies in US, Sweden, and UK showed that unprotected sexual intercourse rate ranged from $14.0 \%$ to $38.5 \%$ in adolescents $[4,30,31]$. Previous study indicated that knowledge and awareness about HIV/STI were lower in Chinese adolescents, which may partly account for the higher prevalence of unprotected sexual intercourse in our study sample [11,23]. The present study specially examined the associations between substance use and ongoing unprotected sexual intercourse, where it was shown that substance use, and specifically often/usually cigarette smoking and illicit drug use were strong risk factors for unprotected sexual intercourse, which was in agreement with previous studies $[1,5]$. A more recent study particularly 
Table 3 Prevalence of sexual/drug-use behaviors of study participants

\begin{tabular}{|c|c|c|c|c|}
\hline & Total $(\mathrm{N}=2688)$ & Males $(\mathrm{N}=1324)$ & Females $(\mathrm{N}=1329)$ & $x^{2}$ \\
\hline \multicolumn{5}{|l|}{ Part one Sexual behaviors in lifetime; $n(\%)$} \\
\hline 1. Sexual intercourse in lifetime & & & & $76.95 *$ a \\
\hline Ever had & $188(7.0)$ & $146(11.0)$ & $33(2.5)$ & \\
\hline Never had & $2500(93.0)$ & $1178(89.0)$ & $1296(97.5)$ & \\
\hline 2. Gender of the sexual partner lifetime & & & & $3.25^{b}$ \\
\hline Heterosexual partner & $152(80.5)$ & $121(83.0)$ & $31(70.0)$ & \\
\hline Homosexual partner & $11(6.0)$ & $7(4.7)$ & $4(15.0)$ & \\
\hline Both & $25(13.5)$ & $18(12.3)$ & $7(15.0)$ & \\
\hline 3. Sexual intercourse partners in lifetime & & & & $0.62^{b}$ \\
\hline One & $113(60.3)$ & $86(59.0)$ & $27(68.4)$ & \\
\hline Two & $10(5.3)$ & $8(5.7)$ & $2(5.3)$ & \\
\hline$\geq$ three & $65(34.4)$ & $52(35.2)$ & $13(26.3)$ & \\
\hline 4. Unprotected sexual intercourse & & & & $0.01^{\mathrm{a}}$ \\
\hline Ever had & $80(42.4)$ & $62(42.5)$ & $18(52.1)$ & \\
\hline Never had & $108(57.6)$ & $84(57.5)$ & $24(57.9)$ & \\
\hline \multicolumn{5}{|l|}{ 5. Age of the first sexual intercourse } \\
\hline$\leq 14$ years & $31(16.4)$ & $26(17.4)$ & $5(22.0)$ & $3.22^{\mathrm{b}}$ \\
\hline $15-17$ years & $92(49.2)$ & $67(46.2)$ & $25(57.1)$ & \\
\hline$\geq 18$ years & $65(34.4)$ & $53(36.4)$ & $12(20.8)$ & \\
\hline 6. Age of the first sexual partner & & & & $0.95^{b}$ \\
\hline$\leq 14$ years & $30(15.8)$ & $23(16.0)$ & $7(15.0)$ & \\
\hline $15-17$ years & $82(43.6)$ & $66(45.3)$ & $16(35.0)$ & \\
\hline$\geq 18$ years & $76(40.6)$ & $57(38.7)$ & $19(50.0)$ & \\
\hline \multicolumn{5}{|l|}{ Part two Sexual behaviors in last three months; $\mathrm{n}(\%)$} \\
\hline 1. Antecedent sexual behaviors with heterosexual partner & & & & $32.38^{* * a}$ \\
\hline No/occasional & $2548(94.8)$ & $1225(92.5)$ & $1294(97.4)$ & \\
\hline Often/usually & $140(5.2)$ & $99(7.5)$ & $35(2.6)$ & \\
\hline 2. Antecedent sexual behaviors with homosexual partner & & & & $12.90 *$ a \\
\hline No/occasional & $2642(98.3)$ & 1309 (98.9) & 1306 (98.3) & \\
\hline Often/usually & $46(1.2)$ & $15(1.1)$ & $23(1.7)$ & \\
\hline \multicolumn{5}{|l|}{ 3. Sexual intercourse } \\
\hline Ever had & $137(5.1)$ & $102(7.7)$ & $25(1.9)$ & $46.75^{* * a}$ \\
\hline Never had & $2551(94.9)$ & $1222(92.3)$ & $1304(98.1)$ & \\
\hline \multicolumn{5}{|l|}{ 4. Among these sexual intercourses } \\
\hline (1) Heterosexual intercourse & & & & $17.85^{* * a}$ \\
\hline Ever had & $121(88.1)$ & $98(96.0)$ & $17(68.0)$ & \\
\hline Never had & $16(11.9)$ & $4(4.0)$ & $8(32.0)$ & \\
\hline (2) Homosexual intercourse & & & & $2.93^{a}$ \\
\hline Ever had & $59(42.9)$ & $38(37.1)$ & $14(56.0)$ & \\
\hline Never had & $78(57.1)$ & $64(62.9)$ & $11(44.0)$ & \\
\hline (3) Sexual intercourse partners (\%) & & & & $0.76^{b}$ \\
\hline One & $69(50.7)$ & $50(49.1)$ & $15(61.5)$ & \\
\hline
\end{tabular}


Table 3 Prevalence of sexual/drug-use behaviors of study participants (Continued)

\begin{tabular}{|c|c|c|c|c|}
\hline Two & $9(6.7)$ & $7(7.0)$ & $2(7.7)$ & \\
\hline$\geq$ three & $59(42.7)$ & $45(43.9)$ & $8(30.8)$ & \\
\hline (4) Unprotected sexual intercourse & & & & $0.88^{a}$ \\
\hline Ever had & $58(42.1)$ & $41(39.7)$ & $13(52.0)$ & \\
\hline Never had & $79(57.9)$ & $61(60.3)$ & $12(48.0)$ & \\
\hline (5) Sexual intercourse while drunk & & & & $4.77^{* a}$ \\
\hline Ever had & $54(39.6)$ & $45(43.9)$ & $5(20.0)$ & \\
\hline Never had & $83(60.4)$ & $57(56.1)$ & $20(80.0)$ & \\
\hline (6) Sexual intercourse with high-risk partners & & & & $1.35^{\mathrm{a}}$ \\
\hline Ever had & $35(25.9)$ & $28(27.3)$ & $4(16.0)$ & \\
\hline Never had & $102(74.1)$ & $74(72.9)$ & $21(84.0)$ & \\
\hline \multicolumn{5}{|c|}{ Part three Substance use behaviors in last three months; $\mathrm{n}(\%)$} \\
\hline 1. Injection drug use & & & & $18.43^{* * a}$ \\
\hline Ever had & $38(1.4)$ & $29(2.2)$ & $4(0.3)$ & \\
\hline Never had & $2650(98.6)$ & $1295(97.8)$ & $1325(99.7)$ & \\
\hline 2. Oral/rhinal drug use & & & & $13.64 * a$ \\
\hline Ever had & $32(1.2)$ & $25(1.9)$ & $5(0.4)$ & \\
\hline Never had & $2656(98.8)$ & $1299(98.1)$ & $1324(99.6)$ & \\
\hline 3. Cigarette smoking & & & & $24.75^{* * a}$ \\
\hline No/occasional & $2634(98.0)$ & $1282(96.8)$ & $1322(99.5)$ & \\
\hline Often/usually & $54(2.0)$ & $42(3.2)$ & $7(0.5)$ & \\
\hline 4. Alcohol drinking & & & & $71.84 * a$ \\
\hline No/occasional & $2580(96.0)$ & $1231(93.0)$ & $1321(99.4)$ & \\
\hline Often/usually & $108(4.0)$ & $93(7.0)$ & $8(0.6)$ & \\
\hline
\end{tabular}

Antecedent sexual behaviors refers to kiss and petting.

Unprotected sexual intercourse refers to the sexual intercourse without condemn use.

High-risk partners refer to people with HIV/AIDS/STI, people with drug use, and people with multiple.

sexual partners.

a $2 * 2$ Chi-square Test.

${ }^{b} \mathrm{~K}^{*} 2$ Chi-square Test.

${ }^{*} \mathrm{P}<0.05$.

${ }^{* *} \mathrm{P}<0.01$.

examined the relationship between substance use and HIV/STI-related sexual risky behaviors among a national sample of sexually active adolescents in American rural settings, where it was similarly found that smoking could increase the likelihood of unprotected sex [32]. There is increasing evidence that illicit drug use may be a risk factor for unprotected sexual intercourse in adolescents by cross-sectional studies $[1,8]$. A quantitative longitudinal design was implemented to assess causal relationship between illicit drug use and risky sexual behaviors in a sample of gay and bisexual men at 4, 8, and 12 months post-baseline, which indicated that illicit drug use could predict subsequent risky sexual behaviors, such as unprotected sex and multiple-partner sex [33].

The results of our study showed that in our sampled adolescents, $1.4 \%$ ever had injection drug use, $1.2 \%$ ever had oral/rhinal drug use, $2.0 \%$ often/usually smoked, and $4.0 \%$ often/usually drunk in last three months. A possible interpretation regarding the mechanisms of association between substance use and high-risk sexual behaviors was that substance use can adversely affect adolescents' decision-making and result to compromised judgment [34]. In addition, problem behavior theory suggested that problem behaviors (including sexual and substance use activities) tended to cluster and co-occur in adolescents, which was associated with adolescents' personality, behavior, and the perceived environment [35].

Among the adolescents with experience of sexual intercourse in lifetime or during last three months, 39.7\% and $49.4 \%$ ever had sexual intercourses with two or more sexual partners, respectively, which was obviously higher prevalent and beyond our expectation. To the best of our knowledge, this study was the first to report Chinese adolescents' risky sexual behaviors, so, it was unavailable to do comparison with other researches in China. Studies in other countries similarly demonstrated that multiple- 
Table 4 Factors associated with ongoing unprotect sexual intercourse and multiple sexual intercourse during past 3 months by logistic regression models

\begin{tabular}{|c|c|c|c|c|}
\hline & \multicolumn{2}{|c|}{ Unprotect sexual intercourse in last three months } & \multicolumn{2}{|c|}{ Multipal sexual partner in last three months } \\
\hline & B & OR $(95 \% \mathrm{Cl})$ & $\bar{B}$ & OR $(95 \% \mathrm{Cl})$ \\
\hline Age & & NS & & NS \\
\hline \multicolumn{5}{|l|}{ Gender } \\
\hline Male & & NS & & NS \\
\hline Female & & 1.00 & & 1.00 \\
\hline \multicolumn{5}{|l|}{ Father's educational level } \\
\hline Middle school and below & & NS & & NS \\
\hline High school & & NS & & NS \\
\hline College and above & & 1.00 & & 1.00 \\
\hline \multicolumn{5}{|l|}{ Mother's educational level } \\
\hline Middle school and below & & NS & & NS \\
\hline High school & & NS & & NS \\
\hline College and above & & 1.00 & & 1.00 \\
\hline \multicolumn{5}{|l|}{ Family income status } \\
\hline Low $(<1500)$ & & NS & & NS \\
\hline Medium (1500-2499) & & NS & & NS \\
\hline High $(\geq 2500)$ & & 1.00 & & 1.00 \\
\hline \multicolumn{5}{|l|}{ Family structure } \\
\hline Single parent family & & NS & & NS \\
\hline Nuclear/large family & & 1.00 & & 1.00 \\
\hline \multicolumn{5}{|c|}{ Cigarette smoking in last three months } \\
\hline Often/usually & 0.18 & $2.04(1.02-4.00) *$ & & NS \\
\hline No/occasional & & 1.00 & & 1.00 \\
\hline \multicolumn{5}{|l|}{ Drunk in last three months } \\
\hline Often/usually & & NS & & NS \\
\hline No/occasional & & 1.00 & & 1.00 \\
\hline \multicolumn{5}{|c|}{ Illict drug use in last three months } \\
\hline Ever had & 0.24 & $2.44(1.15-5.26) *$ & & NS \\
\hline Never had & & 1.00 & & 1.00 \\
\hline \multicolumn{5}{|c|}{ Age of the first sexual intercourse in lifetime } \\
\hline$\leq 14$ years & & NS & 0.89 & $2.45(1.79-7.08) *$ \\
\hline $15-17$ years & & NS & 0.68 & $1.97(1.24-5.73) *$ \\
\hline$\geq 18$ years & & 1.00 & & 1.00 \\
\hline \multicolumn{5}{|l|}{ Age of the first sexual partner } \\
\hline$\leq 14$ years & & NS & & NS \\
\hline $15-17$ years & & NS & & NS \\
\hline$\geq 18$ years & & 1.00 & & 1.00 \\
\hline
\end{tabular}

Family income was expressed in RMB(yuan)/person/month.

$\mathrm{OR}$, odds ratio.

$\mathrm{Cl}$, confidence interval.

NS: no significance.

${ }^{*} \mathrm{P}<0.05$. 
partner sex was a common practice in sexual active adolescents [28-30,34-36]. For example, a study in Swiss high school students found that the median number of sexual partners was two in students who had sexual intercourse experience [30]. In the United States, the prevalence of multi-sexual partner was $33.0 \%-56.0 \%$ in adolescents with sexual intercourse experience [36,37]. In other countries, this rate ranged from $40 \%$ to $75.2 \%$ $[28,29]$. In high-risk adolescent groups, such as delinquent youth and homeless youth, this rate was extraordinarily high and even reached to above 90.0\% [34].

The present study found that younger age of first sexual intercourse was related to an increased tendency of ongoing multiple-partner sexual intercourse. In our sampled adolescents with sexual intercourse experience in lifetime, age of first sexual intercourse was distributed as: $\leq 14$ years (16.4\%), $15-17$ years $(49.5 \%)$, and $\geq 18$ years $(34.4 \%)$. Contrast to a few years ago, age of first sexual intercourse in adolescents of Shanghai urban area were much younger [38,39]. Between 2001 and 2005 , the percentage of adolescents who initiated first sexual intercourse $<18$ years was approximately $20-30 \%$ $[38,39]$. Previous studies suggested that early sexual experience had adverse impact on later sexual activity $[37,38]$. There was evidence that early sexual intercourse was associated with later substance use, inconsistent condemn use, as well as multiple sex partner [40], which supported the finding of our study. Moreover, a more recent study in men who have sex with men (MSM) found that MSM with a history of childhood sex were more likely to report frequent casual partners and therefore more likely to be HIV positive and to engage in unprotect intercourse [41].

Many factors were associated with adolescents' initiation of sexual intercourse: age, ethnicity, gender, substance use, economic status, and sociocultural tradition $[42,43]$. As an Asian country, Chinese society has intrinsic sociocultural values and traditional convention. In Chinese traditional culture, abstain is especially emphasized for unmarried people, especially for females, which is considered to be linked to personal and family honor. However, with the rapid economic development, massive migration, and ongoing acculturation in China, particularly in big Chinese cities (such as Shanghai, Beijing, Guangzhou, and etc.), the traditional conservative value faces challenges. Coming along side an increase in personal freedoms, the spread of the internet, and growing curiosity about overseas norms of behavior, it has contributed to a far more permissive and promiscuous society than was the case in the past. Only a few years ago, the percentage of adolescents who ever had sexual intercourse was ranged from 1.3\% to $4.8 \%$ in high school students of Beijing, Shanghai, and Guangzhou [11-14,22,23]. Compared to their peers a few years ago, adolescents in big Chinese cities nowadays seemed to be becoming more and more sexually active, which may lead to an increase of sexual behaviors and a shift to younger age of first sexual intercourse [11-14,22,23,38,39].

There are several limitations that should be considered in interpreting these results. Firstly, social-desirability bias and inaccuracy may be existed in answering the questionnaires despite guaranteed anonymity. The second limitation existed in study design. The cross-sectional nature of the study precludes inferences on causality. Thirdly, given the cosmopolitan nature of Shanghai in comparison to the rest of the country, and especially compared to rural China, our findings may not reflect the overall practice in China. Finally, our sample limited our analyses of demographic subgroups (senior high school students in urban area of Shanghai) and can not be generalize to other population.

\section{Conclusions}

In conclusion, our findings provided information regarding Chinese adolescents' sexual and substance use behaviors. Compared to their peers of many other countries, Chinese adolescents were in a lower level of prevalence of sexual intercourse, however, some risky sexual behaviors, such as unprotected sex and multiple-partner sex, were were more prevalent among those who are sexually experienced. Taking into account a small proportion of youth in China equaling a very large number, we should not take this finding lightly. In addition, we found that substance use and earlier first sexual intercourse could increase the odds of ongoing unprotected sex and multiple-partner sex, respectively. These results suggested that those adolescents with sexual and substance use behaviors seemed to be problem adolescents. Based on the results, we advocated heightened concerns be target the adolescents, particularly those adolescents with sexual and substance use behaviors. Further research is needed to develop effective interventions for this population to reduce sexual and substance use behaviors, which may have a long beneficial to the control of HIV/STI in China.

\section{Additional file}

Additional file 1: The Adolescents' HIV/STI Risk Behaviors Questionnaire (AHRBQ).

Competing interests

There are not any financial competing interests or non-financial competing interests to declare.

\section{Authors' contributions}

All authors contributed the design of this research. SL drafted the manuscript and has been involved in the interpretation of the data. $\mathrm{HH}$ performed statistical analyses. GX, YC, FH, and XY played a major role in the field survey. All authors read and approved the final manuscript. 


\section{Acknowledgments}

This study was funded by Grants from MOE - Shanghai Key Laboratory of Children's Environmental Health (06DZ22024), the Key Discipline in Public Health of Shanghai Municipal Education Commission, National Natural Science Foundation of China (81072314, 30700670), Innovation Program of Shanghai Municipal Education Commission (13YZ034), 2009 New Bairenjihua in Shanghai Jiaotong University School of Medicine, and 2012 Shanghai public health academic leader project (GWDTR201222).

\section{Author details}

${ }^{1}$ School of Public Health affiliated with Shangai Jiaotong University School of Medicine, 227 South Chongqing Road, Shangai, People's Republic of China. ${ }^{2} \mathrm{MOE}$ - Shangai Key Laboratory of Children's Environmental Health, Xinhua Hospital, Shangai Jiao Tong University School of Medicine, Shangai, People's Republic of China. 'Shangai Municipal Health Bureau, 227 South Chongqing Road, Shanghai, People's Republic of China.

Received: 31 July 2012 Accepted: 25 March 2013

Published: 4 April 2013

\section{References}

1. Baskin-Sommers A, Sommers I: The co-occurrence of substance use and high-risk behaviors. J Adolesc Health 2006, 38:609-611.

2. Caminis A, Henrich C, Ruchkin V, Schwab-Stone M, Martin A: Psychosocial predictors of sexual initiation and high-risk sexual behaviors in early adolescence. Child Adolesc Psychiatry Ment Health 2007, 1:14.

3. Connell CM, Gilreath TD, Hansen NB: A multiprocess latent class analysis of the co-occurrence of substance use and sexual risk behavior among adolescents. J Stud Alcohol Drugs 2009, 70:943-951.

4. Eaton DK, Kann L, Kinchen S, Shanklin S, Ross J, Hawkins J: Centers for Disease Control and Prevention (CDC). Youth risk behavior surveillanceUnited States, 2007. MMWR Surveillance Summaries 2008, 57:1-131.

5. Kogan SM, Brody GH, Chen YF, Grange CM, Slater LM, DiClemente RJ: Risk and protective factors for unprotected intercourse among rural African American young adults. Public Health Rep 2010, 125:709-717.

6. Shurtleff D, Lawrence D: HIV and Substance Abuse: A Commentary. Curr HIV Res 2012:10.

7. Campo-Arias A, Ceballo GA, Herazo E: Prevalence of pattern of risky behaviors for reproductive and sexual health among middle- and highschool students. Rev Lat Am Enfermagem 2010, 18:170-174.

8. Yi S, Poudel KC, Yasuoka J, Palmer PH, Yi S, Jimba M: Role of risk and protective factors in risky sexual behavior among high school students in Cambodia. BMC Public Health 2010, 10:477.

9. Fortenberry JD: Adolescent substance use and sexually transmitted diseases at risk: A review. J Adolesc Health 1995, 16:304-308.

10. Weinstock $H$, Berman S, Cates W: Sexually transmitted diseases among American youth: incidence and prevalence estimates, 2000. Perspect Sex Reprod Health 2004, 36:6

11. Jing WU, Xiong GL, Shi SH: Study on sexual knowledge, attitudes and behaviors of adolescents. CJCHC 2007, 15:120-124 [in Chinese]

12. Li FG, Wang JJ, Mai JC, Wang XL, Li LC, Fang YH: Investigation on adolescent health risk behaviors in Guangzhou city. CJCHC 2007, 23:166-168 [in Chinese]

13. Li FJ, Wang JJ, Mai JC, Wang XW, Li LC, Fang YH, Ka DE: Investigation on adolescent health risk behaviors in Guangzhou city. CJCHC 2007, 23:166-168 [in Chinese].

14. Luo N, Wang SX, Yu XM: Sexual behaviors and correlating factors in HaiDian district of Beijing city. CJCHC 2006, 40:371-372 [in Chinese].

15. Liu Z, Zhou W, Lian Z, Mu Y, Cai Z, Cao J: The use of psychoactive substances among adolescent students in an area in the south-west of China. Addiction 2001, 96:247-250.

16. Wang $\mathrm{ZH}$ : An analysis of current situations of drug abuse among the young adolescents in Yunnan province. JYPOA 2007, 1:52-55 [in Chinese]

17. Shao Y, Jia Z: Challenges and opportunities for HIV/AIDS control in China. Lancet 2012, 379:804.

18. Wang L, Wang N: HIV/AIDS epidemic and the development of comprehensive surveillance system in China with challenges. Chin Med J (Engl) 2010, 123:3495-3500.

19. Watts J: Sex, drugs, and HIV/AIDS in China. Lancet 2008, 371:103-104.

20. Homma Y, Wang N, Saewyc E, Kishor N: The relationship between sexual abuse and risky sexual behavior among adolescent boys: a metaanalysis. J Adolesc Health 2012, 51:18-24.
21. Li S, Huang H, Cai $Y, X u$ G, Huang F, Shen $X$ : Characteristics and determinants of sexual behavior among adolescents of migrant workers in Shangai (China). BMC Public Health 2009, 9:195

22. Sun $L$, Zhu HB, Zhang CY, Li JK, Zhao P, Tang MG: Investigation on adolescent health risk behaviors in SiChuan province. CJCHC 2006, 27:1069-1072 [in Chinese].

23. Wang P, Zheng YF, Ying P: A survey of attitude and knowledge for AIDS and sexual behaviors among middle school students in Luoyang City. Chinese Hospital Statistics 2006, 13:20-23 [in Chinese].

24. Giannotta F, Ciairano S, Spruijt R, Spruijt-Metz D: Meanings of sexual intercourse for Italian adolescents. J Adolesc 2009, 32:157-169.

25. Palen $L A$, Smith EA, Caldwell LL, Flisher AJ, Wegner $L$, Vergnani $T$ : Inconsistent reports of sexual intercourse among South African high school students. J Adolesc Health 2008, 42:221-227.

26. Guiella G, Madise NJ: HIV/AIDS and Sexual-Risk Behaviors among Adolescents: Factors influencing the use of condoms in Burkina Faso. Afr J Reprod Health 2007, 11:182-196.

27. Fatusi AO, Blum RW: Predictors of early sexual initiation among a nationally representative sample of Nigerian adolescents. BMC Public Health 2008, 8:136

28. Aras S, Semin S, Gunay T, Orcin E, Ozan S: Sexual attitudes and risk-taking behaviors of high school students in Turkey. J Sch Health 2007, 77:359-366.

29. Aras S, Orcin E, Ozan S, Semin S: Sexual behaviors and contraception among university students in Turkey. J Biosoc Sci 2007, 39:121-135.

30. Haggstrom-Nordin E, Hanson U, Tyden T: Sex behavior among high school students in Sweden: improvement in contraceptive use over time. J Adolesc Health 2002, 30:288-295.

31. Wellings K, Nanchahal K, Macdowall W, McManus S, Erens B, Mercer CH, et al: Sexual behavior in Britain: early heterosexual experience. Lancet 2001, 358:1843-1850.

32. Yan AF, Chiu YW, Stoesen CA, Wang MQ: STD-/HIV-related sexual risk behaviors and substance use among U.S. rural adolescents. J Natl Med Assoc 2007, 99:1386-1394.

33. Halkitis PN, Mukherjee PP, Palamar JJ: Longitudinal Modeling of Methamphetamine Use and Sexual Risk Behaviors in Gay and Bisexual Men. AIDS Behav 2009, 13:783-791.

34. Romero EG, Teplin LA, McClelland GM, Abram KM, Welty $\sqcup$, Washburn JJ: A longitudinal study of the prevalence, development, and persistence of HIV/ sexually transmitted infection risk behaviors in delinquent youth: implications for health care in the community. Pediatrics 2007, 119:e1126-e1141.

35. Jessor R, Donovan JE, Costa FM: Beyond Adolescence: Problem Behavior and Young Adult Development. New York: Cambridge University Press; 1991

36. Ford K, Sohn W, Lepkowski J: American adolescents: sexual mixing patterns, bridge patterns, and concurrency. Sex Transm Dis 2002, 29:13-19.

37. Valois RF, Oeltmann JE, Waller J, Hussey JR: Relationship between number of sexual intercourse partners and selected health risk behaviors among public high school adolescents. J Adolesc Health 1999, 25:328-335.

38. Li X: Advanced sex-maturity and increased sexual behaviors in adolescents. CHM 2006, 3:18-21 [in Chinese].

39. Peng NN, Luo CY, Zhu W, Gao GD, Zhou YF: Risk behaviors of adolescents in Shanghai: knowledg, attitudes and behaviors regarding HIV/AIDS and sexual behaviors. Clic J School Doctor 2003, 17:97-99 [in Chinese].

40. O'Donnell L, O'Donnell CR, Stueve A: Early sexual initiation and subsequent sex-related risks among urban minority youth: the reach for health study. Fam Plann Perspect 2001, 33:268-275.

41. Lloyd S, Operario D: HIV Risk among Men Who Have Sex With Men Who Have Experienced Childhood Sexual Abuse: Systematic Review and Meta-Analysis. AIDS Educ Prev 2012, 24:228-241.

42. Yates A: Childhood sexuality. In Child and Adolescent Psychiatry-A Comprehensive Textbook. 3rd edition. Edited by Lewis M. Philadelphia, Pa: Lippincott Williams \& Wilkins; 2002:274-286.

43. Hahm HC, Lahiff M, Barreto RM: Asian American adolescents' first sexual intercourse: gender and acculturation differences. Perspect Sex Reprod Health 2006, 38:28-36.

doi:10.1186/1471-2458-13-295

Cite this article as: Li et al.: Substance use, risky sexual behaviors, and their associations in a Chinese sample of senior high school students. BMC Public Health 2013 13:295. 